\title{
AN EFFICIENCY SHOOTING PROGRAM FOR YOUTH BASKETBALL PLAYERS
}

\author{
Denisa Zambová ${ }^{1}$ and Lubor Tománek ${ }^{1}$
}

${ }^{1}$ Faculty of Physical Education and Sports, Comenius University in Bratislava, Slovak Republic

\section{SUMMARY}

Shooting practice in youth basketball is "cornerstone" for proper shooting technique, likely, enabling the player to get high shooting percentage in a Professional League (adults). The purpose of this study was to verify the efficiency of the shooting fundamental program $(n=18$, age $9.85 \pm .53)$. Experimental groups were used in these results. The results showed the effect of shooting fundamental program. Shooting test the lay-ups after this period of an experiment was increased by +1.83 successful attempts in comparison with the result in the control time $(+1.45)(p<.01)$. These findings show that efficiency of basketball shooting fundamental program increase shooting percentage during the period of an experiment.

Key Words: youth, training process, fundamental skills, fundamentals of shooting, shooting percentage.

\section{INTRODUCTION}

Basketball experts and fans consider shooting the best known fundamental skills in basketball (Krause, Meyer, \& Meyer, 2008). Shooting practice is very important part of practice session at any level of performance, from beginners to professional players. At the beginners' level, basic fundamental skills should be learned, including basics of shooting fundamentals which will be improved in later stages of development.

The elementary school level is from 7 to 10 years old. Children are sensitive for developing their coordination skills, speed and agility during this period of life. Their movements are very efficient and accurate (Kasa, 2006). According to ibidem this period is called »the first time learning effect $\ll$. Young players of this age are able to learn new movements faster with greater effectiveness. It is necessary to focus on specialized training, more than on general preparation (Figure 1).

Preparing for the basketball season for 8-10 years old children should aim to develop and stabilized fundamental skills. The general concept of practice is focused on improvement of fundamental skills learned in pre-season and improved upon in the next level. Ortega, Manuel Palao, Sainz de Baranda, and García (2009), and Cañadas, Parejo, Ibáñez, García, and Feu (2009) shows a tendency of young players coaches to focus on offensive fundamentals.

Accurate shooting can be developed by learning proper shooting technique at a young age. Argaj et al. (2003) emphasize the significance of practicing free throw shooting from distance determined by youth basketball rules.

Filippi and West (2011) recommend the shooting progression practice model as an useful reminder for coaches and players. That improvement happens over time and in progressive manner. Shooting practice model has three stages. Stage one - mechanics practice, stage two - repetition practice, stage three - competitive practice. Third stage is not recommended for young players.

Youth basketball rules respect all biological aspects of young players' bodies. The rules are modified for youth basketball players to support development of proper shooting technique at young ages without over exertion. Youth players practice and play matches on the lover baskets then adults (height of basket is 2.60 meter). During practice they used balls size 5 and 6 . All season should be focused on shooting technique. 
FIGURE 1

Type of physical activity depending on age (Bompa, 2011;

modified by Tománek, Argaj, \& Schnürmacher, 2003)

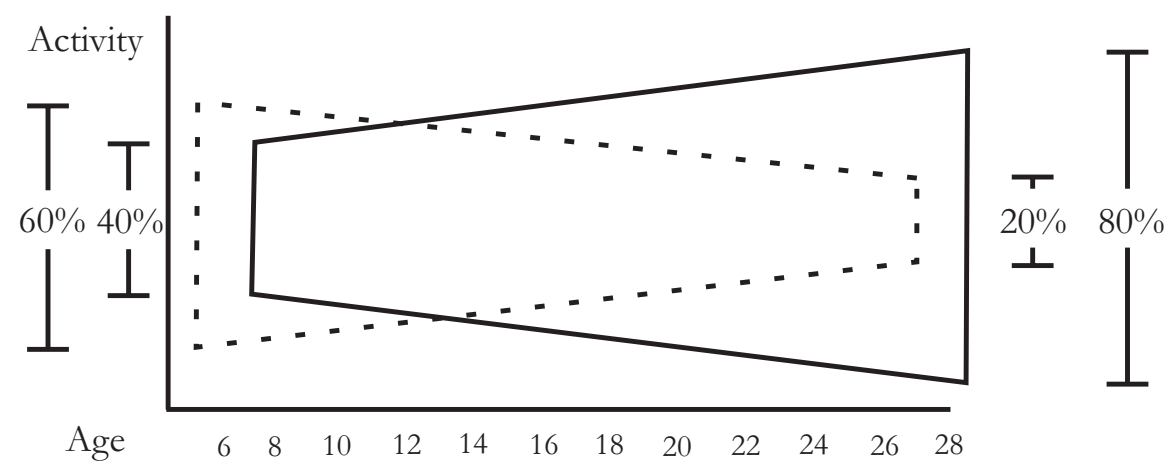

\section{- General preparation \\ - - - Specialized Trainig}

If bad habits are formed in the beginning of learning basketball it will be difficult to eliminate them at an older age. Smooth body movement is necessary for shooting accurately (Mondoni, 2000; Velenský, 1987).

Shooting rhythm is important for building proper skills. Basic components of shooting rhythm are: balanced stance, hand position, body alignment and follow through. Practice goals should be to develop an automatic shooting mechanism (Fillipy \& West, 2011).

According to Mačura (2010) shooting is characterized according to player's movements: set shot (contact with base), the lay-up shot, and jump shot. Argaj et al. (2003) recommends the players to learn the lay-up by dribbling up from the right and left side of the court, the lay-up after passing and after a free throw.

Mondoni (2000), and Vogel and Brown (1992) believe that the lay-ups with right and left hands are necessary fundamental skills for youth basketball players. Mondoni (2000) advises for youth basketball players to learn to shoot after learning basketball skills such as dribbling and passing. Learning fundamental and proper shooting techniques is necessary to get motor skills. To develop excellent shooting techniques requires using various shooting drills, different intensities, aims and great variation.

This research was focused on the efficiency of specific shooting program to improve shooting accuracy of youth basketball players. We tested control and experimental groups and then compared their results. We presumed that the increase of shooting percentage in the experimental group was influenced by the designed shooting fundamental program.

\section{METHOD}

\section{Sample}

Eighteen $(n=18)$ youth basketball players (age $9.85 \pm .53$ years old, height $1.50 \pm .09$ meter, experience $22 \pm 9.43$ months) volunteered and participated in this study. Players participated in 4 practices per week. The length of each practice was 90 minutes. They took part in a regional league for youth basketball for the first time in $2009 / 2010$ season and finished in $4^{\text {th }}$ place.

\section{Procedures}

Modified tests were chosen and implemented to find out the changes in movement abilities and skills (Argaj et al., 2003; Bös, 1988; Brace, 1966a, 1966b): the lay-up test, jumps shot 3 meter test, free throw test. For each test 10 attempts were recorded. Three modified tests were completed during the control and experimental period - the lay up modified test, free throw modified test, and stop jump modified test (Ibid). We used the Wilcoxon $t$-test to monitor significant differences and IBM SPSS 17 operation system for Microsoft Windows.

Single group crossover study-design, 32 weeks in duration, was conducted. Control time period took 16 weeks, and experimental time period took also 16 weeks. We conducted 3 measurements: first, at the beginning of the control period; second, at the end of the control period which was the beginning measurement of the experimental period as well. The last and third measurement, was at the end of experimental period. The control period consisted of 58 practice session, or 87 hours. They played 14 league games wich lasted 9 hours and 20 minutes. Overall 
amount of training load was 102 hours and 20 minutes. The experimental subject was practice focused on the shooting fundamental program and the improved of their shooting technique. The experimental period consisted of 55 practice sessions, or 83 hours and 30 minutes. They played 13 league games which lasted 8 hours and 40 minutes. Overall amount of training load was 96 hours and 40 minutes. Training program was focused on learning and improving fundamental skills and lasted 45 hours and 15 minutes (54.84\%), where shooting practice consisted of 17 hours and 30 minutes in length $(38.12 \%$ ) (Figure 2$)$. Specific shooting fundamental program was aimed at improving basic shooting mechanism and developing shooting technique. We applied 6 shooting drills with variations. Frequency of their application was 84 time during experimental period. Shooting drills were focused on: the lay ups shots, position shot from close and middle range, free throw shots, and under the basket shots form left and right side. Shooting practices were competitive with time and space limitation (Zambová, 2011).

This kind of sport practice was applied in the experimental period by $20.5 \%$ more than in control

FIGURE 2

Ratio of individual skills and other activities during practice (\%).

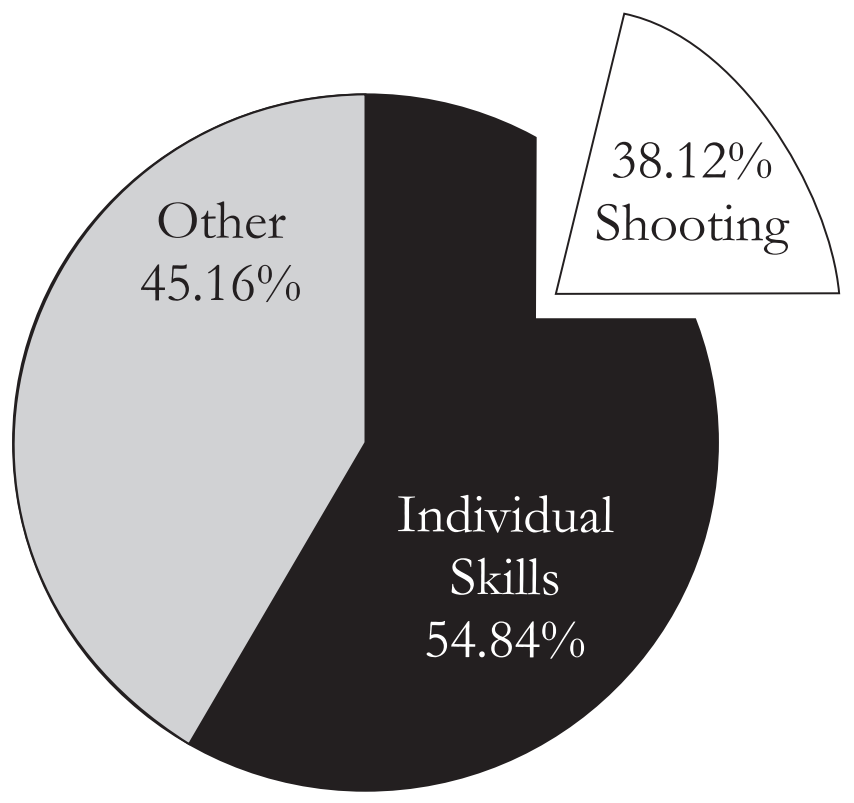

period. The individual skills were raised by $5 \%$. Individual skills were more emphasised in experimental period due to shooting practice programme. As a result we wanted to get more difficult shooting drills compared to control period. Control period was characterized by using shooting drills without time limitation and without pressure of the opponents.

\section{RESULTS}

In the lay up test (Figure 3) in the first measurement, we measured $2.33 \pm 1.75$ of successful attempts (23.30\% shooting percentage). During the second measurement we got $3.78 \pm 1.22$ of successful attempts (37.80\% shooting percentage). In the last and third measurement, there were $7.06 \pm 2.83$ successful attempts (70.60\% shooting percentage). Data showed an increase in shooting accuracy in control period by $1.45(p<.01)$ and in experimental period by $3.28(p$ $<.01)$. Significantly better results of the lay-up modified test were obtained in experimental period $(1.83 ; p<$ $.01)$.

In the stop jump test (Figure 4) in the first measurement, we measured $3.11 \pm 2.44$ of successful attempts $(1.10 \%$ shooting percentage). During the second measurement we got $3.72 \pm 1.53$ of successful attempts (37.20\% shooting percentage). In the last, third measurement we acquired, there were $4.07 \pm$ 1.90 successful attempts (4.70\% shooting percentage). Data results show an increase of shooting accuracy in control period of .61 and in experimental period of .34 shooting attempts. To compare the control and experimental increase we did not achieve any significant improvement of the stop jump modified test during experimental period. The results imply the improvement in the control period of .28 successful attempts. Statistically significant difference was not obtained in stop jump modified test.

In the free throw modified test (Figure 5) in the first measurement, we measured $2.39 \pm 1.34$ successful 
FIGURE 3

The lay-up modified test - increase of shooting percentage.

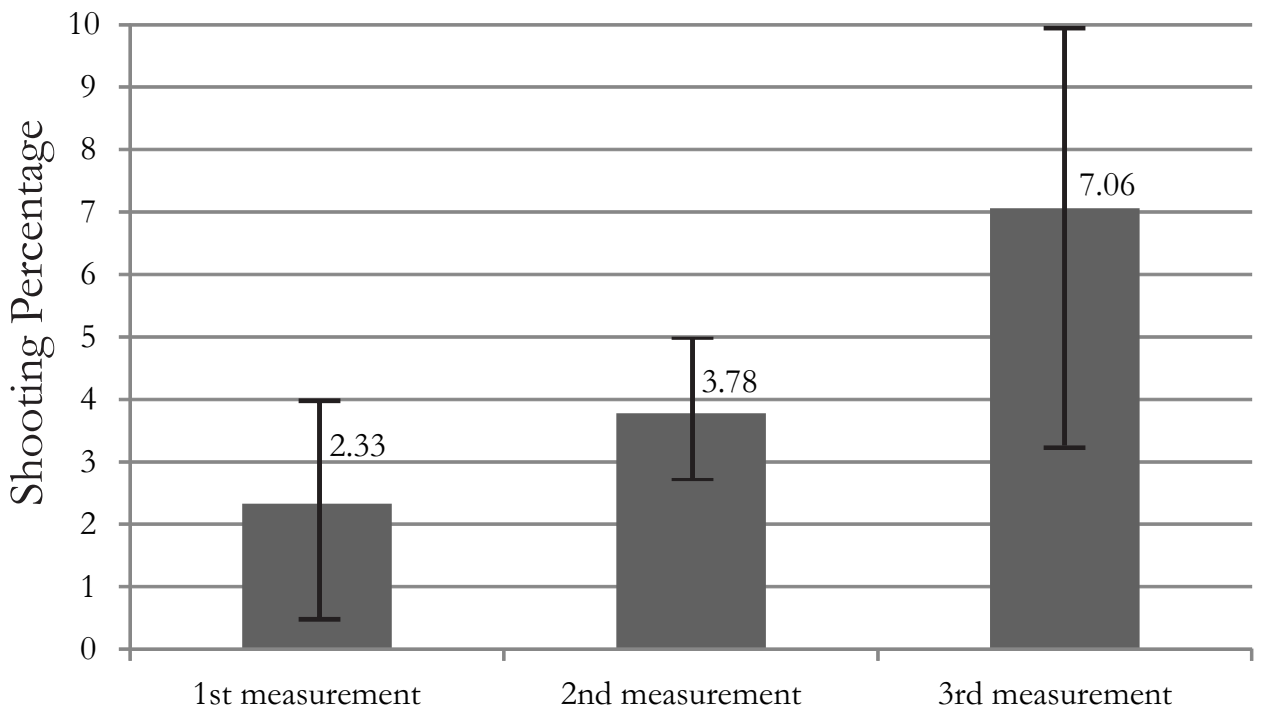

FIGURE 4

Stop jump modified test - increase of shooting percentage.

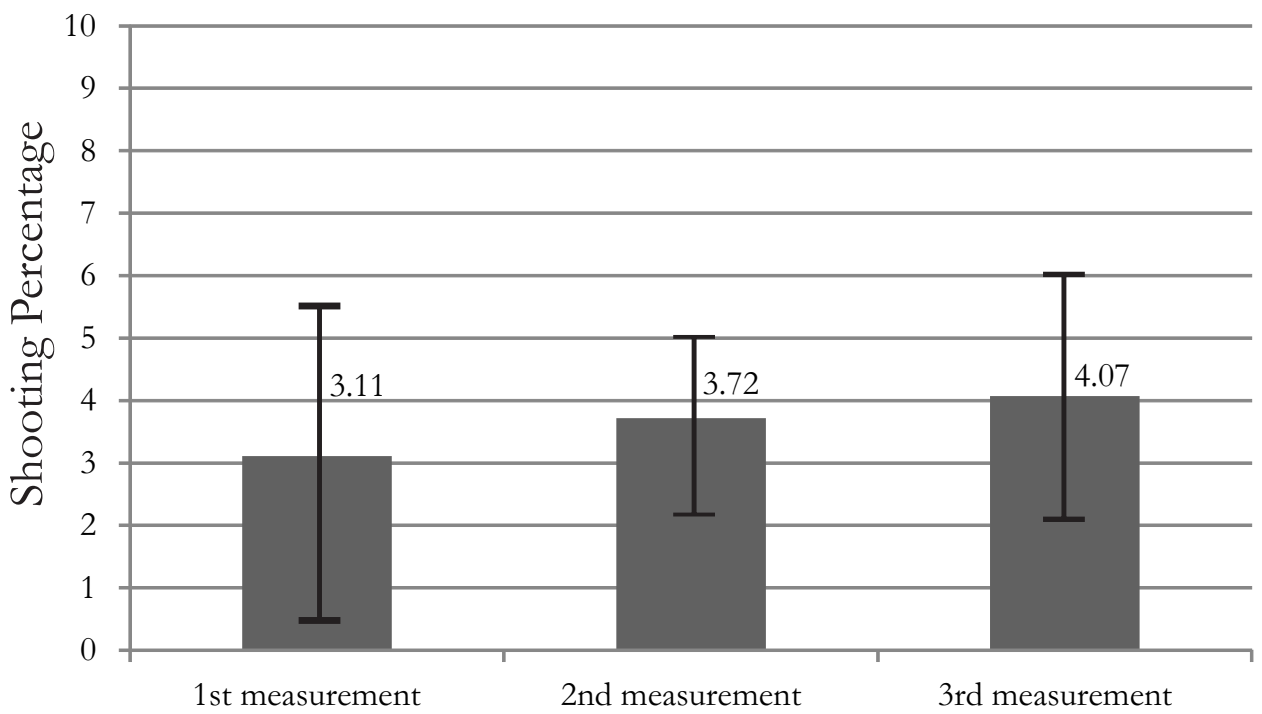

attempts (23.90\% shooting percentage). During the second measurement we got $4.50 \pm 1.62$ successful attempts (45.00\% shooting percentage). The data results showed an increase of shooting accuracy in the control period by $2.11(p<.01)$ shooting attempts, and in the experimental period by $1.45(p<.05)$ shooting attempts. Improvement was not achieved from the free throw modified test in the experimental period. However, we achieved an improvement in control period by $.67(p<.01)$ successfull attempt.

\section{DISCUSSION}

The lay-up modified test result showed improvement in the experimental period of $1.84(p<.01)$ successful attempts, and shooting percentage of $32.89 \%$. Selected competitive drills were applied with ability to resist the defenders' pressure, ability to resist time limitation was effective. Results achieved statistically significant difference. The stop jump test results showed an improvement in the control period of .28 successful attempts, however no improvement was observed in the experimental period. Players reached 37.20\% shooting percentage at the beginning of the experimental 
FIGURE 5

Free throw modified test - increase of shooting percentage.

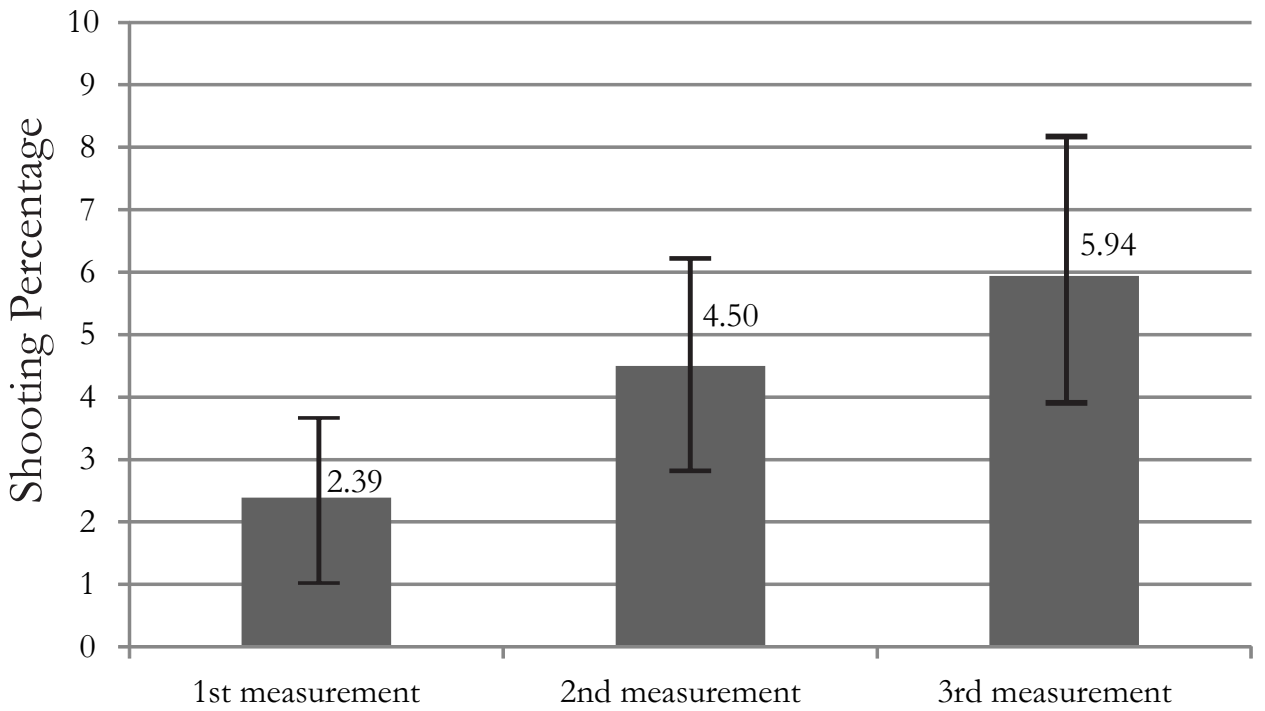

period. Shooting percentage was increased by 3.50\% during the experimental period. The stop jump shooting percentage is sufficient for young players by Krause et al. (2008). Our experimental group of basketball players achieved $40.60 \%$ shooting percentage, which is more than Ibid claimed. The performance of the experimental group reached performance standard rating »excellent for $3.55 \%$ successful attempts. The free throw test showed improvement in the control period by .67 (<.01) successful attempts. Players reached $59.40 \%$ shooting percentage at the end of the experimental period. Free throw shooting percentage was increased by $14.40 \%$ during the experimental period. There was minimal improvement in the free throw shooting percentage. This could be caused by focusing the player's attention on proper shooting technique, not on increasing their shooting percentage. It should be taken into account that after adaptation of free throw shooting, the learning process has not finished. However $60 \%$ shooting percentage of free throw according to consider Ibid is sufficient for young players. Performance of experimental group achieved standard rating »very good « for 6 successful attempts by Argaj et al. (2003). None of the shooting modified tests proved decrease of shooting percentage. There was a slight increase in each measurement. It is important to mention the possibility that the players could achieve low shooting percentage in the beginning of control period due to pre-season. Players have 1.5 month off season, without regular practice. First measurement was realized after two weeks of general practice preparation.

\section{CONCLUSION}

Shooting accuracy is a well known aspect for rating the quality of basketball player and team. Greater percentage of shooting the players achieve the greater is their possibility to play in a professional league. Pavlidou, Michalopoulou, Aggeloussis, and Kioumourtzoglou (2006) demonstrated that there is a great influence of motor movement abilities on basketball skills, because according to mentioned study basketball players had better reaction time in comparison with other participants. Shooting and perception tests showed high correlation dependence as well. We focused on practicing and improving shooting in young basketball players. Results showed an increase in shooting accuracy by applying selected shooting drills. Basketball players showed a significantly better results in the lay-up modified test. They improved in jump shot modified test, and free throw modified test. The study was focused on offense skills, specialized on improvement of shooting in the practice program for youth basketball players. Significantly better result of the lay-ups could be explained by using them very often in that age category. The research confirmed that it was possible to achieved statistically significant progress in practice process by using shooting fundamental program. Male and female players created experimental group in youth basketball category. Combined gender education of youth basketball teams exist in young category. Research is recommended to be completed in other categories, especially in older age groups. Individual improvements could be seen 
during experiment. We achieved improvement with every player. These results could be compared with players in higher categories often using the lay-ups and jump shot from longer distance. Experiment could be repeated in other categories or in older age on same experimental group. Practice manual of shooting drills could be useful for coaches and teachers of physical education.

\section{REFERENCES}

Argaj, G., Bebčáková, V., Mačura, P., Schnurmacher, R., Tománek, L., \& Zusková, K. (2003). Učebné osnovy športovej pripravy v basketbale [Sports preparation curriculum in Basketball]. Nové Zámky: Crocus.

Bös, K. (1988). Der Heidelberger-Basketball-Test (HBT) [The Heidelberg-basketball-test (HBT)]. Leistungssport, 18(2), 17-24.

Brace, D. K. (1966a). Basketabll for Boys - Skills Test Manual. Washington, DC: Aahper.

Brace, D. K. (1966b). Basketabll for Girls - Skills Test Manual. Washington, DC: Aahper.

Cañadas, M., Parejo, I., Ibáñez, S. J., García, J., \& Feu, S. (2009). Relationship between the pedagogical variables of coaching a mini basketball team. Revista de Psicología del Deporte, 18 - suppl, 319-323.

Filippi, A., \& West, J. (2011). Shoot Like the Pross: The Road to a Successful Shooting Technique. Chicaigo, IL: Triummph Books.

Kasa, J. (2006). Antropomotorika

[Anthropomotorics]. 3rd Ed. Bratislava, Slovak Republic: FTVŠ UK

Krause, J., Meyer, D., \& Meyer, J. (2008). Basketball Skills and Drills. Champaign, IL: Human Kinetics.

Mačura, P. (2010). Biomechanika basketbalovej strel'by [Biomechanics of basketball shooting]. Bratislava, Slovak Republic: Univerzita Komenského v Bratislave.
Mondoni, M. (2000). Minibasket. In J. M. Buceta, M. Mondoni, A. Avakumović, and K. László (Eds.), Basketball for young players: Guidelines for coaches (pp. 149-205). Minich, Germany: Interantional Basketball Federation.

Ortega, E., Palao, J. M., de Baranda, S. P. \& García, L. M. (2009). Preferences and level of satisfaction in technical and tactical actions and in type of offense and defense utilized in competition by youth basketball players. Revista de Psicología del Deporte, 18 - suppl., 343-348

Pavlidou, S., Michalopoulou, M., Aggeloussis, N., \& Kioumourtzoglou, E. (2006). Relationship between perceptual and motor abilities on fundamental basketball skills in 8-13 years old children. Inquiries in Sport and Physical Education, (2006), 4, 399-408.

Tománek, L., Argaj, G., \& Schnűrmacher, R. (2003). Sportová priprava v minibasketbale. [Sports preparation in minibasketball]. Bratislava, Slovak Republic: Basketbalový tréner.

Velenský, E. (1987). Basketbal: Novépoznatky a zkušenosti t trénerské práce s drušstvy všech výkonnostnich úrovni [Basketball: New knowledge and experience coaching t work with teams of all levels of performance]. Praha: Olympia.

Vogel, P., \& Brown, E. W. (1992). Planning effective instruction. In K. Garchow and A. Dickenson (Eds.), Youth basketball - A complete handbook (pp. 32-51). Carmel, IN: Cooper Publishing Group.

Zambová, D., Mačura, P., \& Tománek, L. (2011). Program športovej pripravy minibasketbalistov so zameranim na strelbu [The sports training minibasketball players focusing on shooting]. Praha: FTVS Karlova Univerzita.

Zambová, D. (2011). Úcinnost’ programu športovej pripravy mladšch minibasketbalistov [The effectiveness of the program of sports practice younger minibasketball players]. (Unpublished diploma thesis). Faculty of Physical Education and Sports, Comenius University in Bratislava.

Received: February 22, 2012

Revision received: May 2, 2012 Accepted: Jun 15, 2012

Correspodence to: Denisa Zambová, MSc ŠD Lafranconi Náb. Arm. Gen. L. Svobodu 9 81469 Bratislava Slovak Republic E-mail: denisa.zambova@fsport.uniba.sk Phone: 00421740126 